\title{
Strain Hardening and Adiabatic Heating of Stainless Steels After a Sudden Increase of Strain Rate
}

\author{
N. I. Vázquez-Fernández ${ }^{1}$ M. Isakov ${ }^{1} \cdot$ M. Hokka ${ }^{1}$ (i)
}

Received: 17 September 2021 / Accepted: 21 January 2022 / Published online: 4 February 2022

(c) The Author(s) 2022

\begin{abstract}
This study focuses on the strain hardening and adiabatic heating of two stainless steels after a sudden increase of strain rate. Tensile tests were performed where the strain rate was rapidly increased from $\sim 10^{-4} \mathrm{~s}^{-1}$ to $1.3 \times 10^{3} \mathrm{~s}^{-1}$. Synchronized full field strain and temperature measurements were carried out with Digital Image Correlation and Infrared Thermography to analyze the materials behavior immediately after the strain rate jump. The results show that the temperature increases gradually while the strain hardening rate drops immediately after the strain rate jump. The temperature increase due to adiabatic heating does not seem to explain the drop in the strain hardening rate, thus the strain rate seems to have a direct effect on the strain hardening rate of the studied steels.
\end{abstract}

Keywords Strain-induced martensitic phase transformation $\cdot$ Strain hardening $\cdot$ Tensile Split Hopkinson Bar (SHB) $\cdot$ High strain rate $\cdot$ Strain rate jump $\cdot$ Adiabatic heating $\cdot$ Digital image correlation $\cdot$ Infrared thermography

\section{Introduction}

Austenitic stainless steels provide a good combination of mechanical properties and corrosion resistance, and are therefore widely used in, for example, transportation, oil and gas, medical and electrical engineering applications. In metastable alloys the strain-induced martensitic phase transformation produces higher ductility and strength. From the early works of Olson and Cohen [1, 2], a great deal of effort has gone into studying the mechanisms and parameters affecting the strain-induced phase transformation. It is widely known that the phase transformation rate is reduced as the temperature increases $[3,4]$. The phase transformation rate is also reduced when the deformation occurs at high strain rates [5]. At high strain rates, the temperature increases due to adiabatic heating. The dominant theory is that, at high strain rates, the temperature rise due to adiabatic heating increases the stacking fault energy, suppressing the martensitic phase transformation [6-11]. Other researchers

M. Hokka

mikko.hokka@tuni.fi

1 IMPACT - Multiscale Mechanics Research Group, Engineering Materials Science, Faculty of Engineering and Natural Sciences (ENS), Tampere University, POB 589, 33014 Tampere, Finland
[12-15] suggest that also the strain rate itself, and not only the adiabatic heating, has a direct effect on the martensitic phase transformation.

It is evident that more work is needed to quantitatively separate the effects of temperature and strain rate on the martensitic phase transformation. On this line, Isakov et al. [16] performed tensile strain rate jump tests on a AISI 301 steel. In these tests, the strain rate was suddenly increased by several orders of magnitude, from quasi-static to dynamic conditions. The authors observed that the strain hardening rate of the steel decreased instantaneously after the sudden increase of strain rate. A previous study of the current authors showed that the specimen deformed uniformly after the sudden increase of strain rate until necking started [17]. However previous investigations have not been able to provide adequate evidence on what happens to the temperature of the specimen during a rapid change of strain rate. This report provides convincing experimental data which shows that the thermomechanical behavior and especially the adiabatic heating of the two studied austenitic steels is predictable during a sudden increase of strain rate. The results show that the temperature of both steels increases moderately after the strain rate jump, and no unexpected behavior is observed. This indicates clearly that the strain rate jump test can be used for the evaluation of the material behavior. The results show that the instantaneous drop in the strain hardening rate 
observed in the metastable austenitic steel is not caused by sudden increase in the bulk temperature of the specimen.

\section{Materials and Experimental Methodology}

Two standard stainless steel AISI 301 LN (EN 1.4318) and AISI 316 (EN 1.4420) were studied in the 2B cold rolling condition. Tension specimens with a gage length of $8 \mathrm{~mm}$, and a shoulder radius of $2 \mathrm{~mm}$ and a width of $4 \mathrm{~mm}$ were laser cut from $2 \mathrm{~mm}$ sheets provided by Outokumpu Stainless LTD. The rolling direction was parallel to the loading direction. The specimens were tested in tension at a strain rate of $\sim 2 \times 10^{-4} \mathrm{~s}^{-1}$ until reaching a predetermined deformation where the strain rate was suddenly increased up to $1.3 \times 10^{3} \mathrm{~s}^{-1}$ by impacting the striker bar driven by compressed air to the flange at the free end of the incident bar. These strain rate jump tests were performed using a modified Tensile Split Hopkinson Bar (TSHB). Figure 1 shows a schematic picture of the test setup. For further details see ref. [18].

Full field strain and temperature measurements were carried out using Digital Image Correlation (DIC) and Infrared Thermography (IRT). The low rate loading of the test was recorded using two 5 MPix E-lite cameras with $200 \mathrm{~mm}$ lenses at a frame rate of $2 \mathrm{~Hz}$, whereas the high rate loading was recorded using a Photron SA-X2 high speed camera with $100 \mathrm{~mm}$ lens at a frame rate of $90 \mathrm{kHz}$ with a resolution of $640 \times 152$ pixels. A Telops Fast-IR$\mathrm{M} 2 \mathrm{~K}$ infrared camera was imaging the opposite side of the specimen synchronously with the high speed optical camera at $90 \mathrm{kHz}$ with a resolution of $64 \times 4$ pixels. Figure 2 shows the setup used for the full field measurements during the strain rate jump tests.

The strains were obtained with Davis10 (LaVision $\mathrm{GmbH}$ ) software. A high contrast speckle pattern was applied on the specimen surface with a $0.4 \mathrm{~mm}$ tip marker. Before starting each test, the unloaded specimen was imaged with both the low and the high-speed DIC systems. These images were used as the reference image to calculate the strain. The engineering strain on the specimen was calculated by placing a virtual extensometer of $6 \mathrm{~mm}$ length on the same location in both low and highspeed images. A more detailed description of the digital image processing of the images and the use of the virtual extensometer is given in ref. [15].

The thermal data requires a calibration to convert radiometric temperature into true surface temperature. The temperature calibration was performed by heating a specimen slowly while measuring its temperature with the camera and a thermocouple that was spot welded to the surface of the specimen. The details of the calibration can be found in ref. [15].

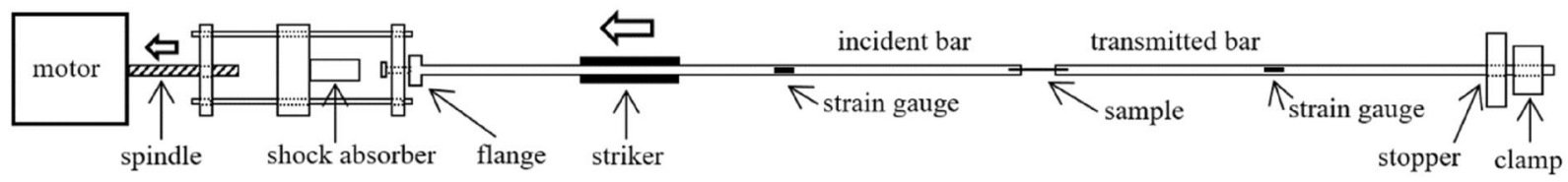

Fig. 1 Schematic picture of the modified Tensile Split Hopkinson Bar, adapted from [17]

Fig. 2 Experimental setup for the full field strain and temperature measurement during the strain rate jump tests [15]

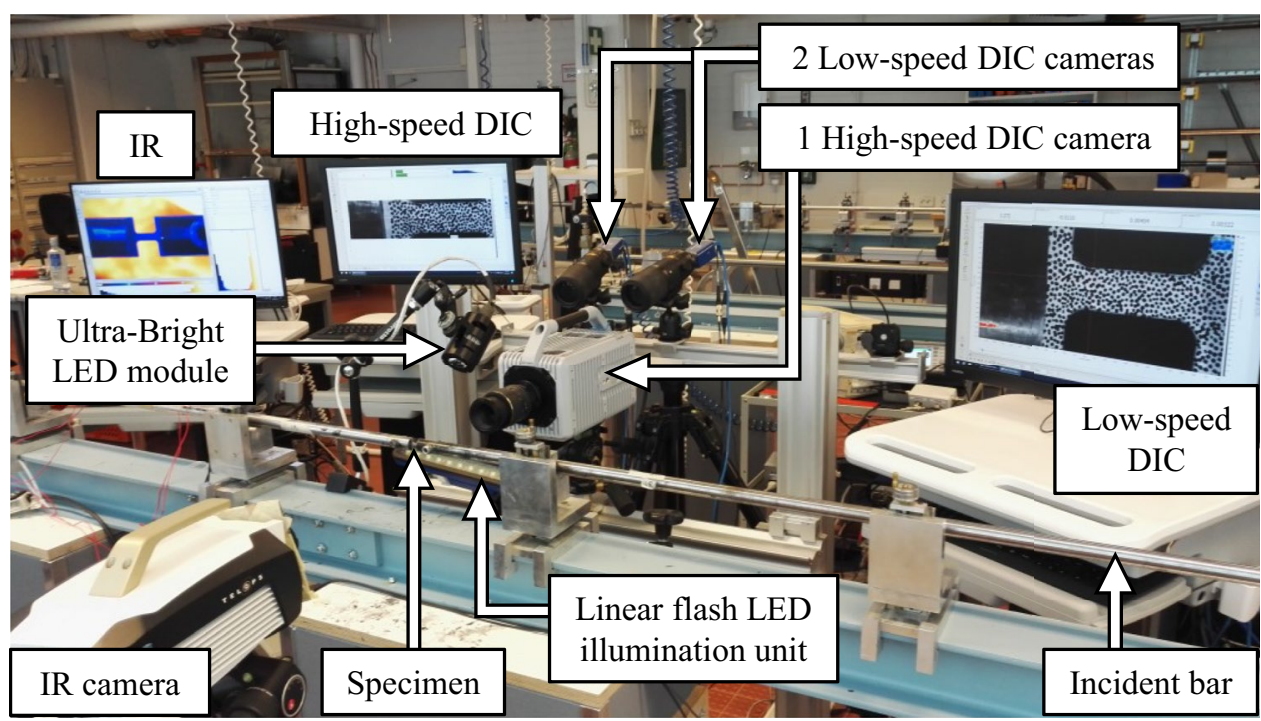




\section{Results}

Figure 3 presents the true stress - true strain and strain hardening rate curves for the studied materials. The strain hardening rate $\left(\frac{\partial \sigma}{\partial \varepsilon}\right)$ was calculated from the stress strain curve. Figure $3 \mathrm{a}$ and $\mathrm{b}$ show the data from tests carried out without the strain rate jump at strain rates of $2 \times 10^{-4} \mathrm{~s}^{-1}$ and $1.3 \times 10^{3} \mathrm{~s}^{-1}$. For the stable 316 steel, increasing the strain rate increases the flow stress without affecting the strain hardening rate of the material. For the metastable 301 steel, however, the stress-strain curve at the lower strain rate has an S-shape due to the strain-induced phase transformation. At $2 \times 10^{-4} \mathrm{~s}^{-1}$, the 301 steel strain hardens notably with the accumulation of plastic strain. At the strain rate of $1.3 \times 10^{3} \mathrm{~s}^{-1}$, the stress-strain curve no longer has the $S$-shape and the strain hardening rate of the material does not increase with further deformation. Figure $3 \mathrm{c}-\mathrm{h}$ show the results of the jump tests where the increase of strain rate occurs after a pre-strain of 0.10 (c-d), 0.20 (e-f), and around 0.30 (g-h). For the stable 316 steel, the strain hardening rate seems to be unaffected by the strain rate jump at any studied pre-strain. For the metastable 301, the sudden increase of strain rate at a pre-strain of 0.10 seems to have very little effect on the strain hardening rate, but when the sudden increase of strain rate takes place at 0.20 and 0.30 of prestrain, however, the strain hardening rate drops significantly after jump.

Figure 4 shows the measured temperature increase as a function of true strain during the high rate loading part of the tests. It can be observed that the slope of the temperature increase becomes steeper as the amount of plastic prestrain increases. This can be explained by the increased flow stress after the jump, which increases the amount of mechanical work put into the specimen for further deformation. The temperature increase measured after certain amount of deformation is lower for the stable 316 steel (Fig. 4a) than that measured for the metastable 301 steel (Fig. 4b). However, for all the tests, both with and without strain rate jump, the temperature increases gradually once the high rate loading starts. After the first $0.05 \mathrm{~mm} / \mathrm{mm}$ of true strain, the highest measured temperature increase is $12 \mathrm{~K}$. The resolution, accuracy and uncertainties related to the measurements are discussed in detail in ref. [19].

\section{Discussion}

A clear decrease in the strain hardening rate can be observed in the strain rate jump experiments of the metastable stainless steel, which indicates that the rate at which the microstructure evolves changes dramatically when the strain rate is increased. This is caused by the changes in the phase transformation rate which decreases significantly at high strain rate [14]. However, the immediate decrease in the strain hardening rate cannot be explained by macroscopic heating of the specimen, as the bulk temperature does not increase suddenly during the strain rate jump. Instead, a gradual temperature increase is observed. Therefore, this finding suggests that either the strain rate itself affects the dynamics of the strain induced martensite transformation and/or that the adiabatic heating may be heterogeneous and some local 'hot spots' are formed in the microstructure. These locally heated areas then may affect the transformation behavior more strongly than what the global or average heating suggests. Further investigations on the local microstructure level deformation and adiabatic heating are needed. 

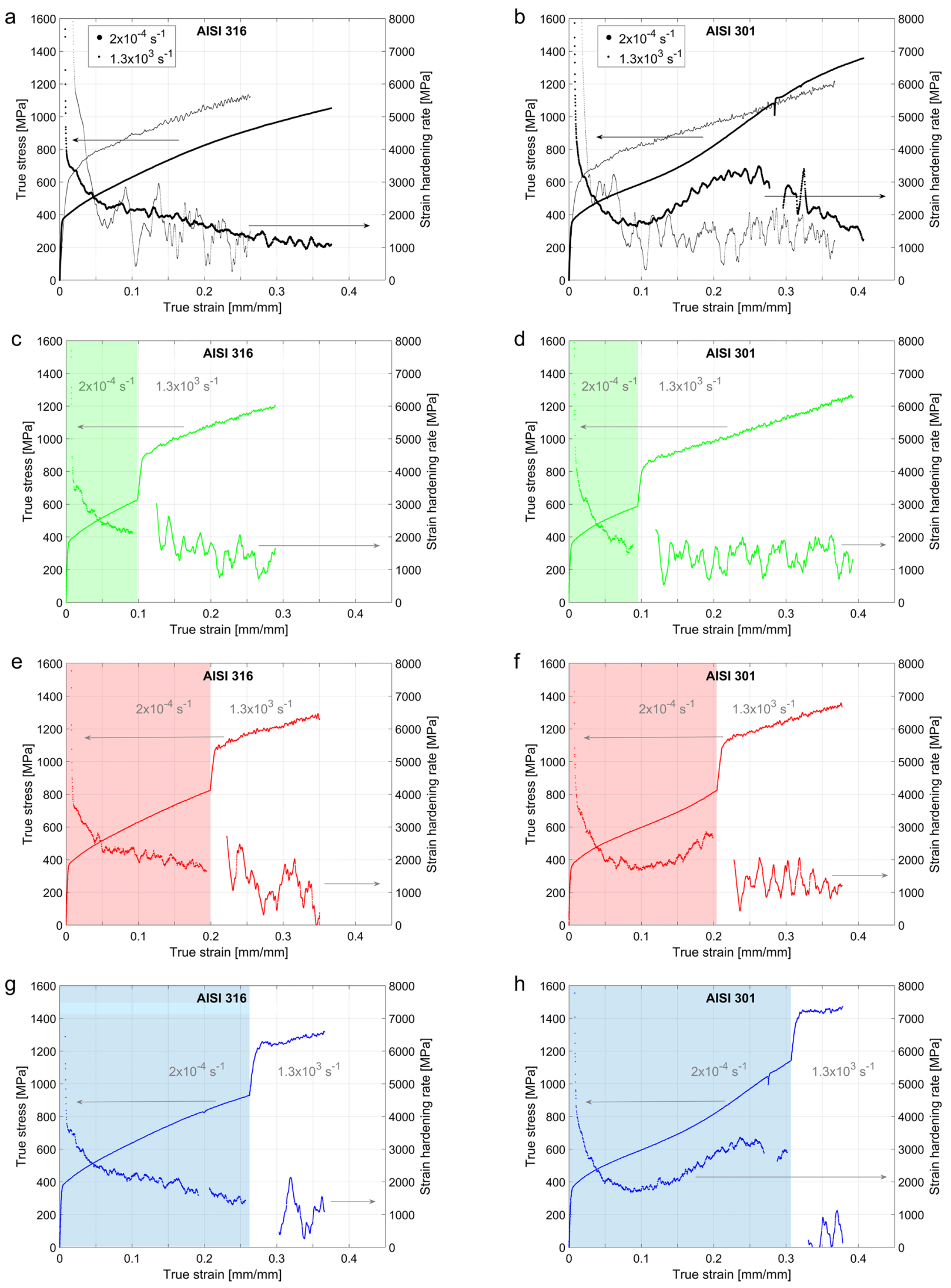
4Fig. 3 True stress-true strain curves and strain hardening rates of the stable 316 steel (on the left) and the metastable 301 steel (on the right) at the constant strain rates of $2 \times 10^{-4} \mathrm{~s}^{-1}$ and $1.3 \times 10^{3} \mathrm{~s}^{-1}$ (a) b), and strain rate jumps at the true strain of, approximately, 0.10 (c, d), $0.20(\mathbf{e}, \mathbf{f})$, and $0.30(\mathbf{g}, \mathbf{h})$

\section{Conclusions}

This study led to the following conclusions:

- The bulk heating of the specimen does not suddenly increase during or after a large upward strain rate jump, instead the temperature rises gradually, as is expected based on the conversion of plastic deformation work into heat.

- The results indicate that the global adiabatic heating is not responsible for the sudden change in the strain hardening and phase transformation rates that is observed in a strain rate jump test of metastable austenitic steels.

The processed data is available through ref. [20].
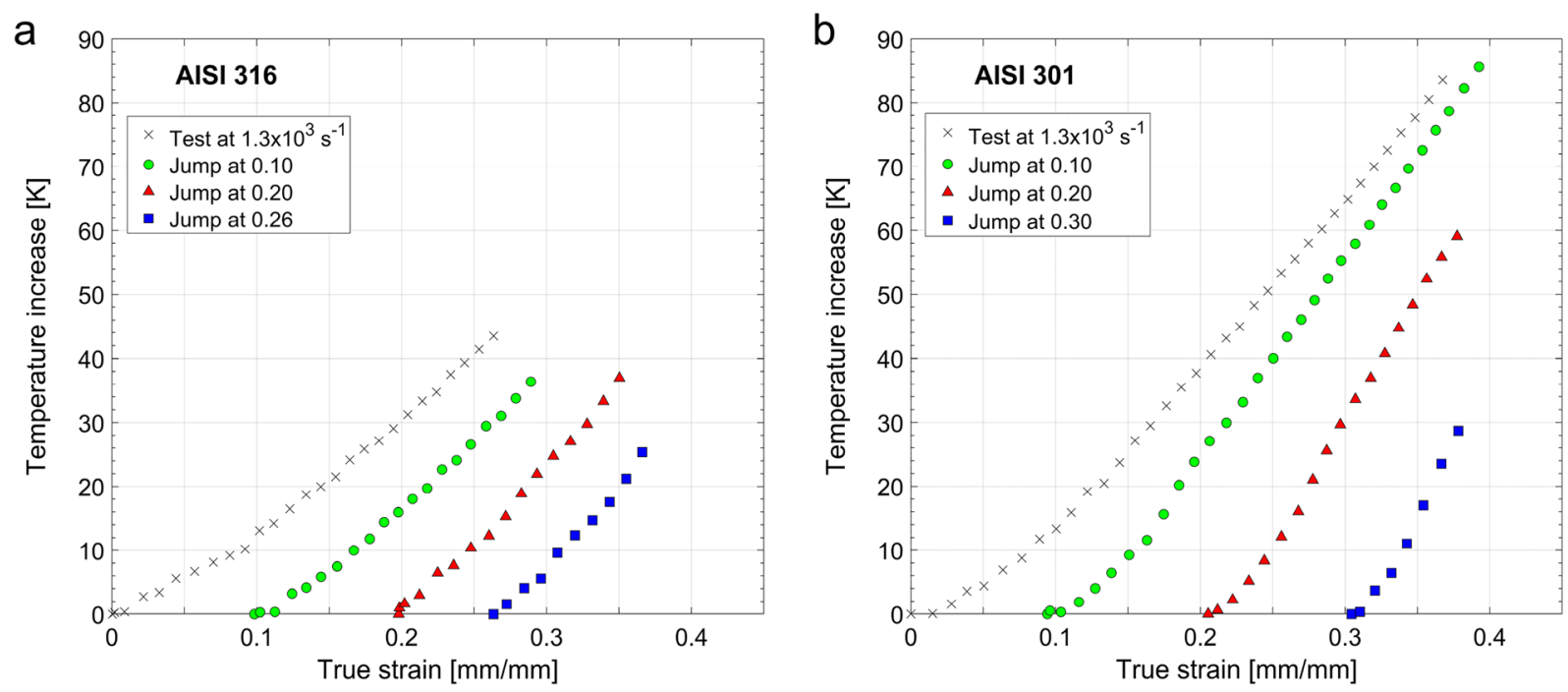

Fig. 4 Temperature increase as a function of true strain during high rate loading of the tests for $\mathbf{a}$ the stable 316 steel and $\mathbf{b}$ the metastable 301 steel. The specimen was at room temperature $(298 \mathrm{~K})$ at the beginning of the test 
Funding Academy of Finland, Research Council for Natural Sciences and Engineering, 294845, Mikko Hokka.

Open Access This article is licensed under a Creative Commons Attribution 4.0 International License, which permits use, sharing, adaptation, distribution and reproduction in any medium or format, as long as you give appropriate credit to the original author(s) and the source, provide a link to the Creative Commons licence, and indicate if changes were made. The images or other third party material in this article are included in the article's Creative Commons licence, unless indicated otherwise in a credit line to the material. If material is not included in the article's Creative Commons licence and your intended use is not permitted by statutory regulation or exceeds the permitted use, you will need to obtain permission directly from the copyright holder. To view a copy of this licence, visit http://creativecommons.org/licenses/by/4.0/.

\section{References}

1. Olson GB, Cohen M (1972) A mechanism for the strain-induced nucleation of martensitic transformations. J Less-Common Metals 28:107-118. https://doi.org/10.1016/0022-5088(72)90173-7

2. Olson GB, Cohen M (1975) Kinetics of strain-induced martensitic nucleation. Metall Trans A 6:791-795. https://doi.org/10.1007/ BF02672301

3. J. Talonen, Effect of strain-induced $\alpha$ '-martensite transformation on mechanical properties of metastable austenitic stainless steels, Helsinki University of Technology, 2007. http://urn.fi/urn:nbn:fi: tkk-009284.

4. Martin S, Wolf S, Martin U, Krüger L, Rafaja D (2016) Deformation mechanisms in austenitic TRIP/TWIP steel as a function of temperature, metallurgical and materials transactions a: physical metallurgy and materials. Science 47:49-58. https://doi.org/10. 1007/s11661-014-2684-4

5. Hecker SS, Stout MG, Staudhammer KP, Smith JL (1982) Effects of strain state and strain rate on deformation-induced transformation in 304 stainless steel: Part I Magnetic measurements and mechanical behavior. Metall Transac A 13:619-626. https://doi. org/10.1007/BF02644427

6. Talyan V, Wagoner RH, Lee JK (1998) Formability of stainless steel. Metall and Mater Trans A 29:2161-2172. https://doi.org/ 10.1007/s11661-998-0041-1

7. Lichtenfeld JA, Van Tyne CJ, Mataya MC (2006) Effect of strain rate on stress-strain behavior of alloy 309 and 304L austenitic stainless steel. Metall and Mater Trans A 37:147-161. https://doi. org/10.1007/s11661-006-0160-5

8. Soleimani M, Kalhor A, Mirzadeh H (2020) Transformationinduced plasticity (TRIP) in advanced steels: a review. Mater Sci Eng, A 795:140023. https://doi.org/10.1016/j.msea.2020.140023

9. Talonen J, Nenonen P, Pape G, Hänninen H (2005) Effect of strain rate on the strain-induced $\gamma \rightarrow \alpha^{\prime}$-martensite transformation and mechanical properties of austenitic stainless steels, Metallurgical and Materials Transactions A: Physical Metallurgy and Materials. Science 36:421-432. https://doi.org/10.1007/s11661-005-0313-y

10. Quitzke C, Schröder C, Ullrich C, Mandel M, Krüger L, Volkova O, Wendler M (2021) Evaluation of strain-induced martensite formation and mechanical properties in $\mathrm{N}$-alloyed austenitic stainless steels by in situ tensile tests. Mater Sci Eng, A 808:140930. https://doi.org/10.1016/j.msea.2021.140930

11. Radajewski M, Eckner R, Decker S, Wendler M, Krüger L (2019) Influence of temperature and strain rate during thermomechanical treatment of a metastable austenitic TRIP steel compacted by SPS/FAST. Adv Eng Mater 21:1-9. https://doi.org/10.1002/adem. 201800617

12. M. Hokka (2008) Effects of strain rate and temperature on the mechanical behavior of advanced high strength steels, Tampere University of Technology

13. M. Isakov (2012) Strain rate history effects in a metastable austenitic stainless steel, Tampere University of Technology

14. Vázquez-Fernández NI, Nyyssönen T, Isakov M, Hokka M, Kuokkala V-T (2019) Uncoupling the effects of strain rate and adiabatic heating on strain induced martensitic phase transformations in a metastable austenitic steel. Acta Mater 176:134-144. https://doi. org/10.1016/j.actamat.2019.06.053

15. Vázquez-Fernández NI (2020) Effects of strain rate and adiabatic heating on the strain-induced martensitic phase transformation in austenitic stainless steels. Tampere University 176:134-144

16. Isakov M, Hiermaier S, Kuokkala V-T (2015) Effect of strain rate on the martensitic transformation during plastic deformation of an austenitic stainless steel, metallurgical and materials transactions a: physical metallurgy and materials. Science 46A:2352-2355. https://doi.org/10.1007/s11661-015-2862-z

17. Vazquez Fernandez NI, Isakov M, Hokka M, Kuokkala V-T (2018) Strain rate jump tests on an austenitic stainless steel with a modified tensile Hopkinson split bar. EPJ Web of Conferences. 183:02026. https://doi.org/10.1051/epjconf/201818302026

18. Isakov M, Kokkonen J, Östman K, Kuokkala V-T (2016) Strain rate change tests with the Split Hopkinson Bar method. The European Physical Journal Special Topics 225:231-242. https://doi. org/10.1140/epjst/e2015-99999-х

19. Soares G, Vazquez N, Hokka M (2021) Simultaneous full-field strain and temperature measurements in high strain rate testing. Adv Exper Impact Mech. https://doi.org/10.1016/B978-0-12823325-2.00004-2

20. N. Vazquez-Fernandes, M. Isakov, M. Hokka, Stress, Strain, and Temperature measurement data for AISI 301 and AISI 316 stainless steels from tension tests with a sudden increase of strain rate. Raw data related to this publication is available at https://doi.org/ 10.5281/zenodo.5775407

Publisher's Note Springer Nature remains neutral with regard to jurisdictional claims in published maps and institutional affiliations. 